\title{
МОДЕЛИ БИЗНЕС-ПРОЦЕССОВ ПО ОСУЩЕСТВЛЕНИЮ РЕЙТИНГОВОГО ОЦЕНИВАНИЯ ДЕЯТЕЛЬНОСТИ ОРГАНИЗАЦИЙ МЕДИКО-СОЦИАЛЬНОГО ПРОФИЛЯ
}

\section{BUSINESS PROCESS MODELS FOR THE ACTIVITIES RATING OF MEDICAL AND SOCIAL ORGANIZATIONS}

\section{A. Konovalov}

O. Romashkova

Summary. The article discusses approaches to modeling the main processes of medical institutions to support management decisions at the regional level and the formation of rating indicators for individual health organizations. In order to automate the main management processes, database models have been developed for the information system for rating the activities of medical and social organizations.

Keywords: healthcare organization, management, information system, rating indicators.

\section{Введение}

Д ля разработки модели существующих бизнес-процессов по осуществлению рейтингового оценивания деятельности организаций медико-социального профиля для управления региональной здравоохранительной системой был использован программный продукт CA ERWin Process Modeler и выбраны методологии IDEF0 и IDEF3 [1-3].

На рисунке 1 представлена контекстная диаграмма верхнего уровня, отображающая осуществление рейтингового оценивания деятельности организаций медико-социального профиля для управления региональной здравоохранительной системой в целом.

После того, как процесс в целом был представлен контекстной диаграммой верхнего уровня, необходимо разбить его на отдельные подпроцессы и разработать соответствующие им диаграммы декомпозиции.
Коновалов Артем Алексеевич

Аспирант, ГАОУ ВО «Московский городской педагогический университет (МГПУ)», г. Москва bernadott94@yandex.ru

Ромашкова Оксана Николаевна

Д.т.н., профессор, ФГБОУ ВО «Российская академия народного хозяйства и государственной службы при

Президенте РФ (РАНХИГС)», г. Москва ox-rom@yandex.ru

Аннотация. В статье рассматриваются подходы к моделированию основных процессов деятельности медицинских учреждений для поддержки управленческих решений регионального уровня и формирования рейтинговых показателей отдельных организаций здравоохранения. С целью автоматизации основных управленческих процессов разработаны модели базы данных для информационной системы рейтингового оценивания деятельности организаций медико-социального профиля.

Ключевые слова: организация здравоохранения, управление, информационная система, рейтинговые показатели.

\section{Моделирование прочессов рейтингового оченивания Аеятельности организаший меАико-сочиального профиля}

В результате декомпозиции блока «Осуществлять рейтинговое оценивание деятельности организаций медико-социального профиля для управления региональной здравоохранительной системой» была создана дочерняя диаграмма декомпозиции уровня А0 (рисунок 2), где представлены основные блоки, которые характеризуют данный вид деятельности:

1. Оценить управление организациями и содержанием услуг [4];

2. Оценить медицинский персонал организаций и актуальность подходов;

3. Оценить профпригодность персонала;

4. Оценить научную эффективность организаций;

5. Составить итоговую оценку здравоохранительной системы региона. 


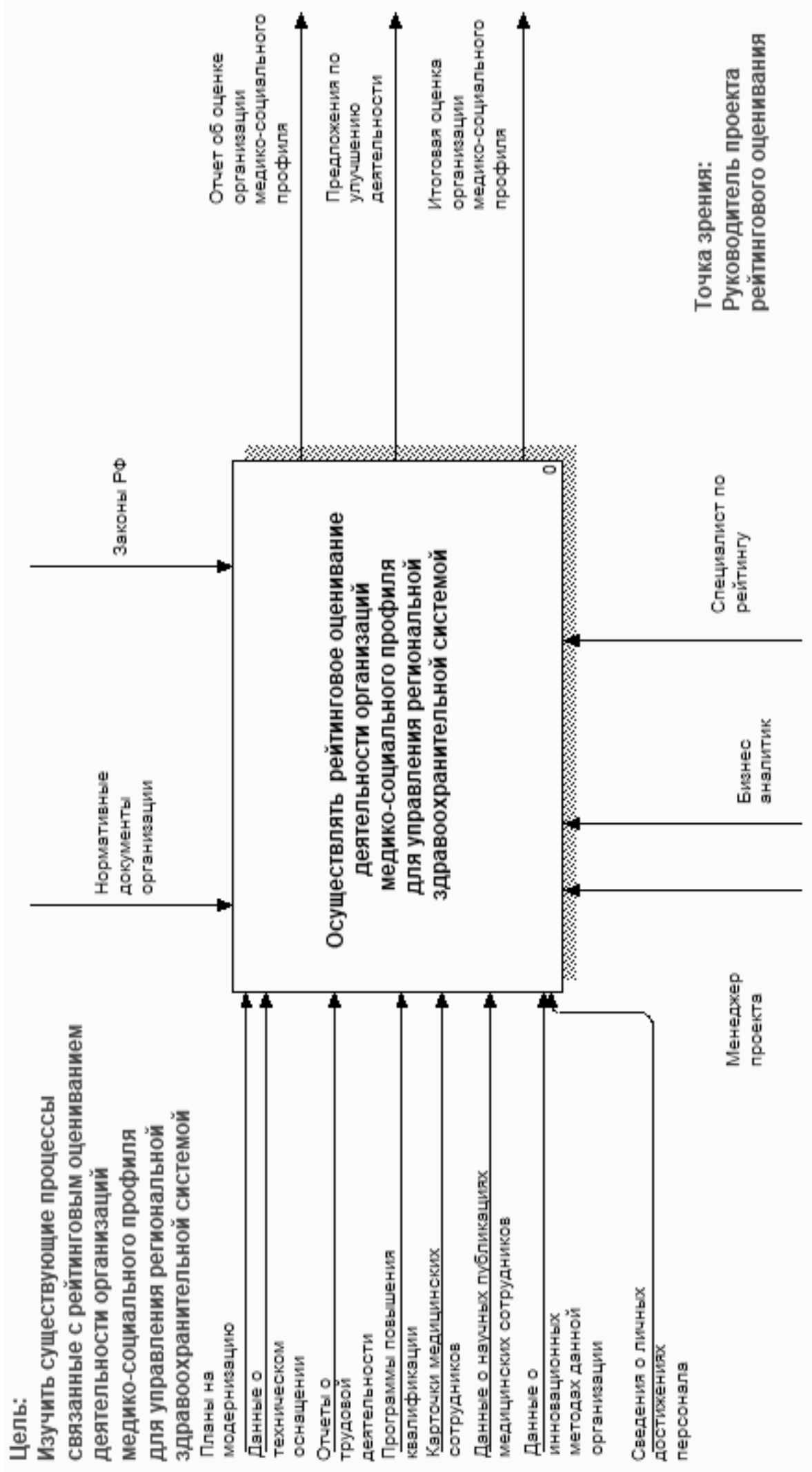

Рис. 1. Контекстная диаграмма верхнего уровня «Осуществлять рейтинговое оценивание деятельности организаций медико-социального профиля для управления региональной здравоохранительной системой» 


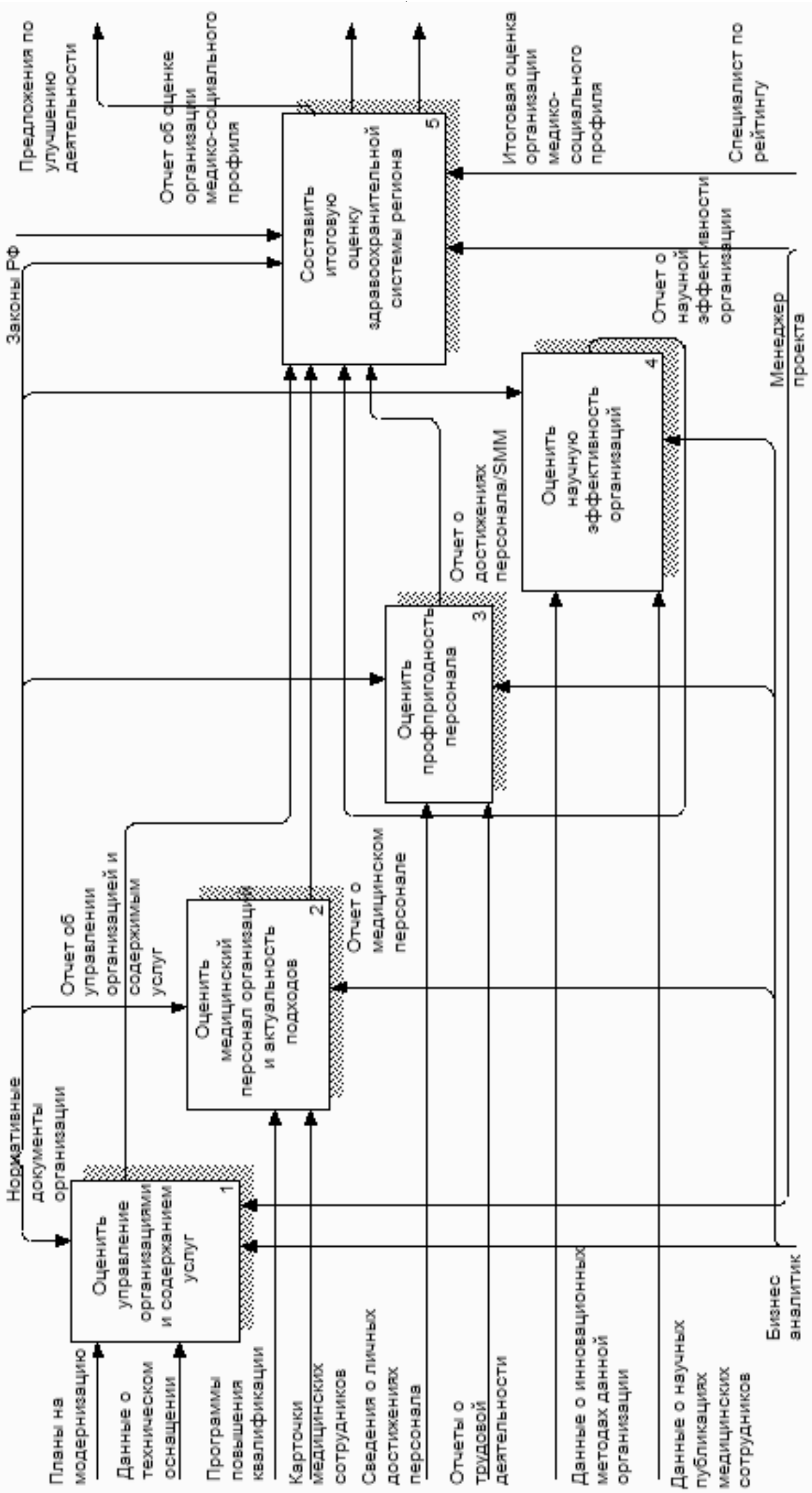

Рис. 2. Диаграмма декомпозиции уровня А0 процесса «Осуществлять рейтинговое оценивание деятельности организаций медико-социального профиля для управления региональной системой здравоохранения» 


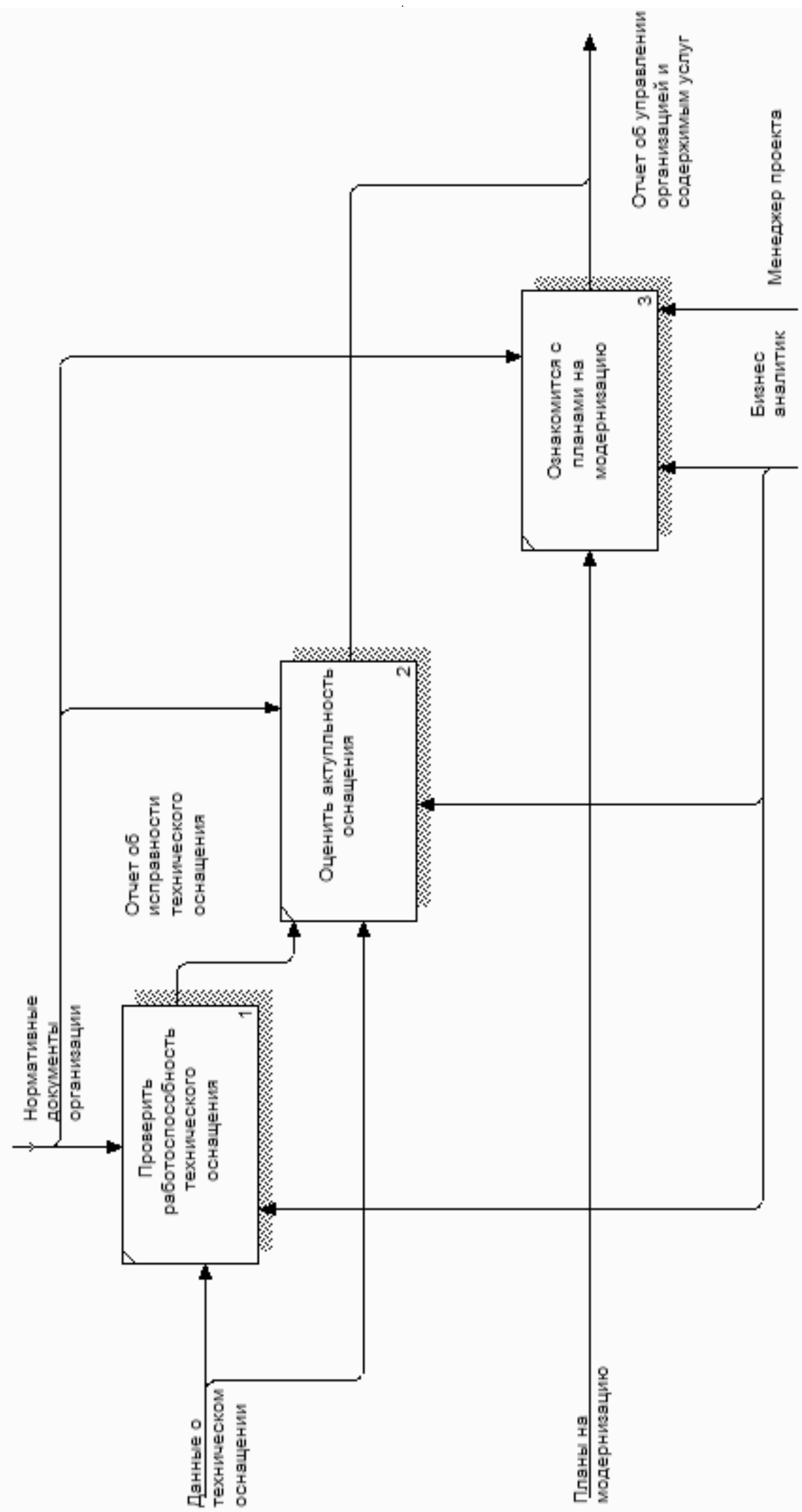

Рис. 3. Диаграмма декомпозиции процесса «Оценить управление организацией и контентом услуг» 


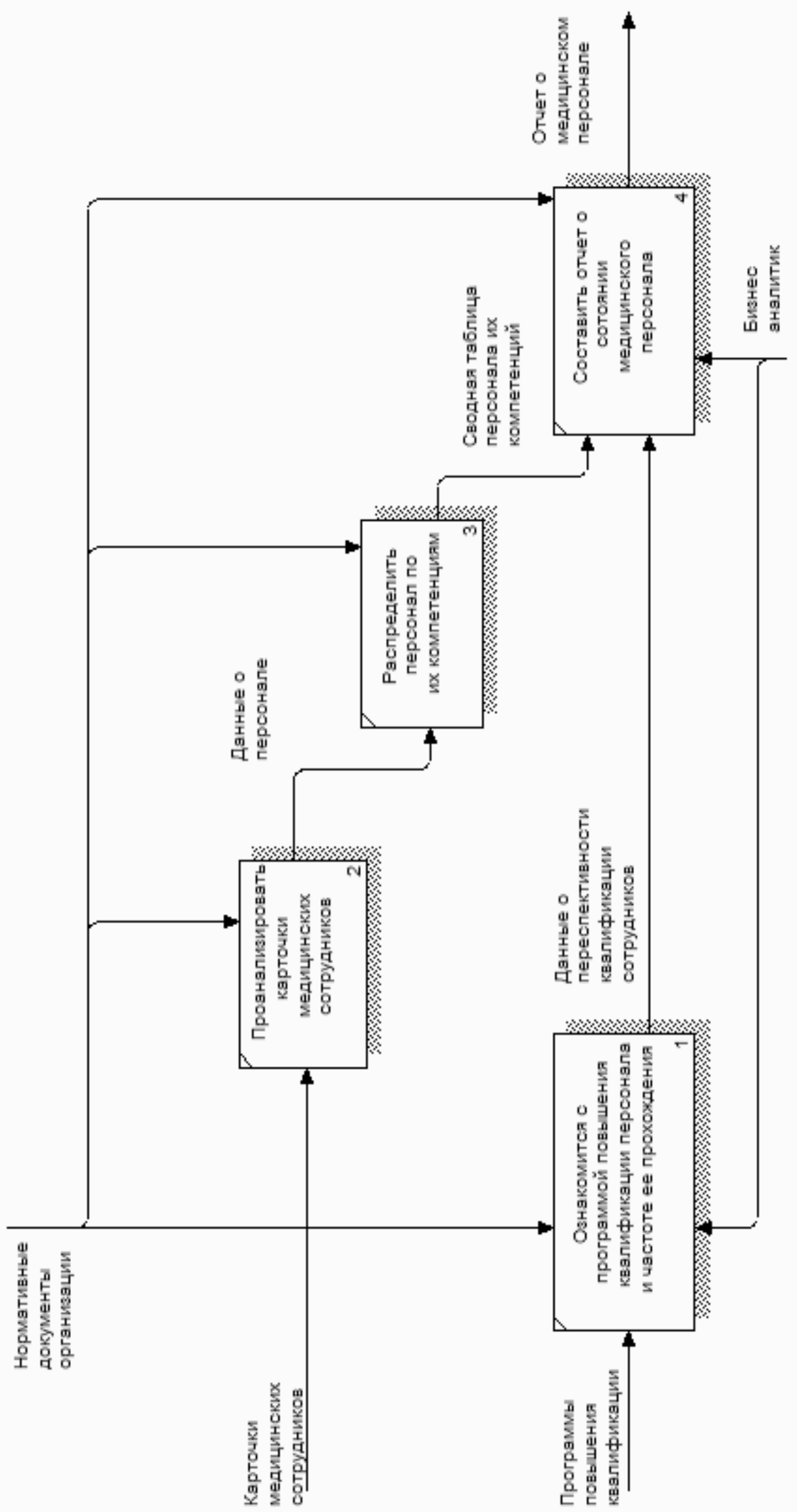

Рис. 4. Дочерняя диаграмма декомпозиции процесса «Оценить медицинский персонал» 


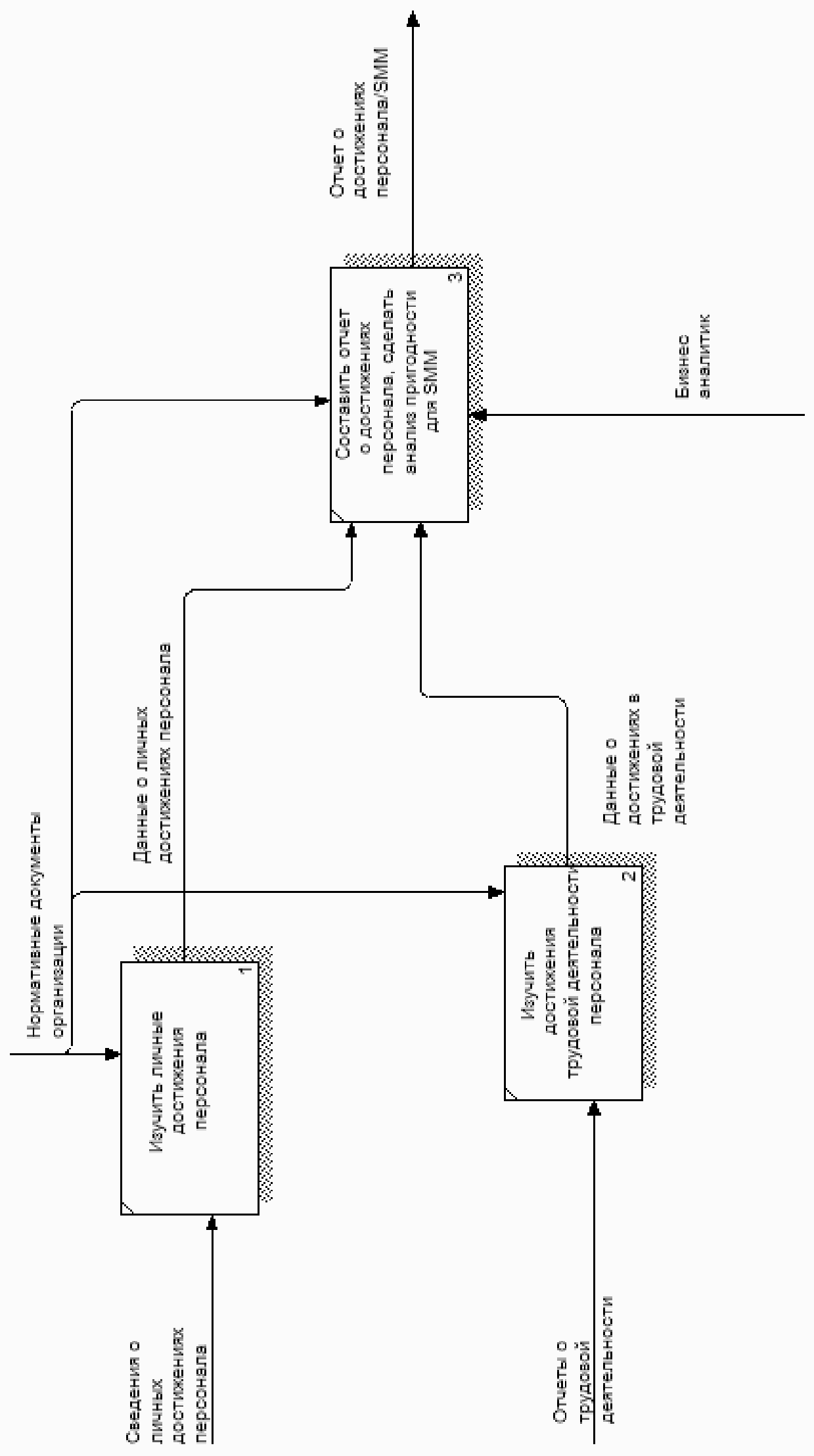

Рис. 5. «Оценить профпригодность персонала» 


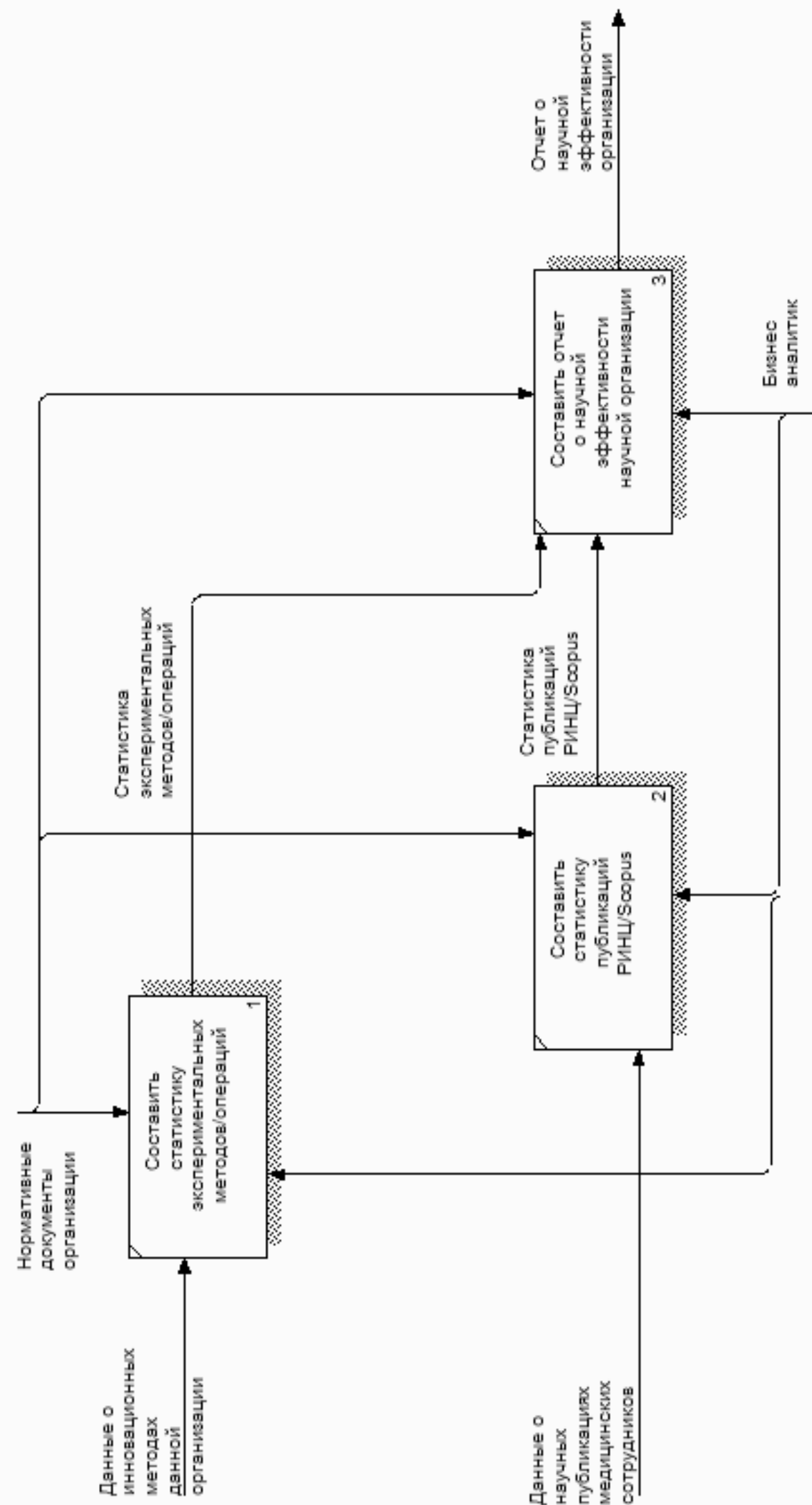

Рис. 6. Диаграмма последовательного описания этапов работ процесса «Оценить научную эффективность организации» 


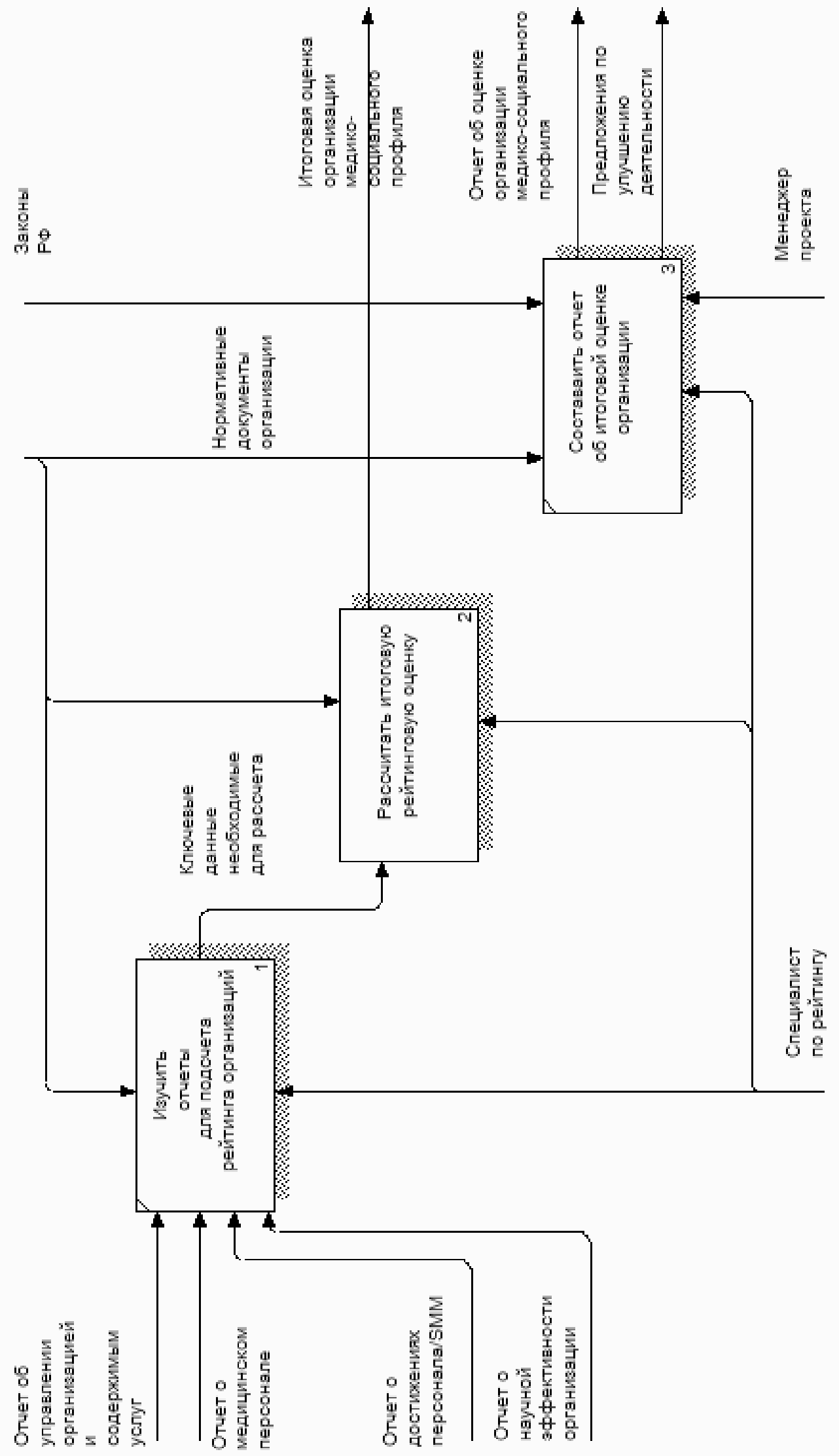

Рис. 7. Диаграмма последовательного описания этапов работ процесса «Составить итоговую оценку» 


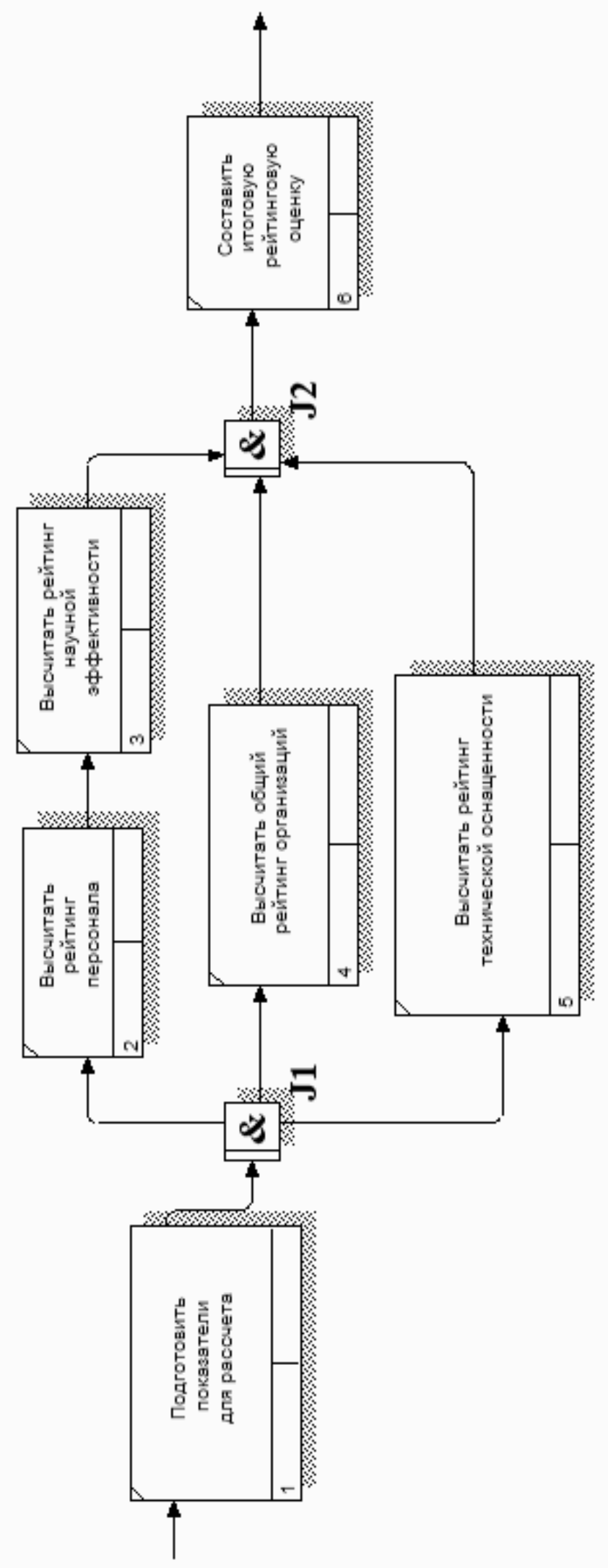

Рис. 8. Дочерняя диаграмма последовательного описания этапов работ процесса «Рассчитать итоговую рейтинговую оценку» 
Таблица 1. Сущности и их определения

\begin{tabular}{|c|c|}
\hline Имя сущности & Определение \\
\hline 1 & 2 \\
\hline Научные достижения сотрудника & $\begin{array}{l}\text { Хранит данные о научном звании, числе публикаций, рейтинге РИНЦ, рейтинге Scopus, } \\
\text { наградах }\end{array}$ \\
\hline Медицинская организация & $\begin{array}{l}\text { Хранит данные о названии организации, количестве персонала, количестве отделений, } \\
\text { медицинском профиле, типе организации }\end{array}$ \\
\hline План модернизации организации & Хранит данные о сроке проведения модернизации, о бюджете \\
\hline Медицинский сотрудник & Хранит данные о ФИО сотрудника, даты рождения, должности, стажа \\
\hline Рейтинг & Хранит данные об оценке \\
\hline Личные достижения сотрудника & $\begin{array}{l}\text { Хранит данные о достижениях в спортивной сфере, о достижениях в социальной сфере, } \\
\text { семейном положении }\end{array}$ \\
\hline Повышение квалификации сотрудника & Хранит данные о дате, профиле и оценке медицинского сотрудника \\
\hline Экспериментальные методы & $\begin{array}{l}\text { Хранит данные о названии метода, профиле, процента успешности, даты согласования } \\
\text { на проведение }\end{array}$ \\
\hline
\end{tabular}

Далее была разработана диаграмма декомпозиции процесса «Оценить управление организацией и содержимым услуг» в нотации IDEFO (рисунок 3).

Для рейтингового оценивания деятельности организаций медико-социального профиля в целях управления региональной здравоохранительной системой необходимо проверить работоспособность технического оснащения $[5,6]$. На основе отчета об исправности технического оснащения - оценить его актуальность. Далее необходимо ознакомиться с планами на модернизацию.

Следующим этапом моделирования является декомпозиция процесса «Оценить медицинский персонал» (рисунок 4). На основе анализа нормативных документов и личных карточек медицинских сотрудников производится распределение персонала по компетенциям. Параллельно выполняется ознакомление с программой повышения квалификации персонала, периодичностью и частотой ее прохождения. На основании полученных данных составляется отчет о состоянии медицинского персонала.

Ключевым функциональным элементом является процесс «Оценить профпригодность персонала», для которого диаграмма описания последовательности этапов работ представлена на рисунке 5. На основе изучения личных данных персонала и достижений трудовой деятельности персонала составляется отчет о достижениях персонала, делается анализ пригодности для SMM. SMM (Social Media Marketing) - это не просто публикация постов о медицинских услугах, это комплекс мероприятий для продвижения клиники или личного бренда врача в социальных сетях.

На рисунке 6 представлена диаграмма последовательного описания этапов работ процесса «Оценить научную эффективность организации». По данным об инновационных методах данной организации составляется статистика экспериментальных методов/операций $[7,8]$. По полученной информации о научных публикациях медицинских сотрудников составляется статистика РИНЦ/ Scopus. В итоге составляется отчет о научной эффективности организации здравоохранения.

На рисунке 7 представлена диаграмма последовательного описания этапов работ процесса «Составить итоговую оценку». На основе полученных отчетов об управлении организацией и контентом услуг, о медицинском персонале, достижениях персонала/SMM и научной эффективности организации проводится изучение отчетов для подсчета рейтинга организаций. Далее рассчитывается итоговая рейтинговая оценка и составляется отчет об итоговой оценке организации.

На рисунке 8 представлена диаграмма последовательного описания этапов работ процесса «Рассчитать итоговую рейтинговую оценку». 


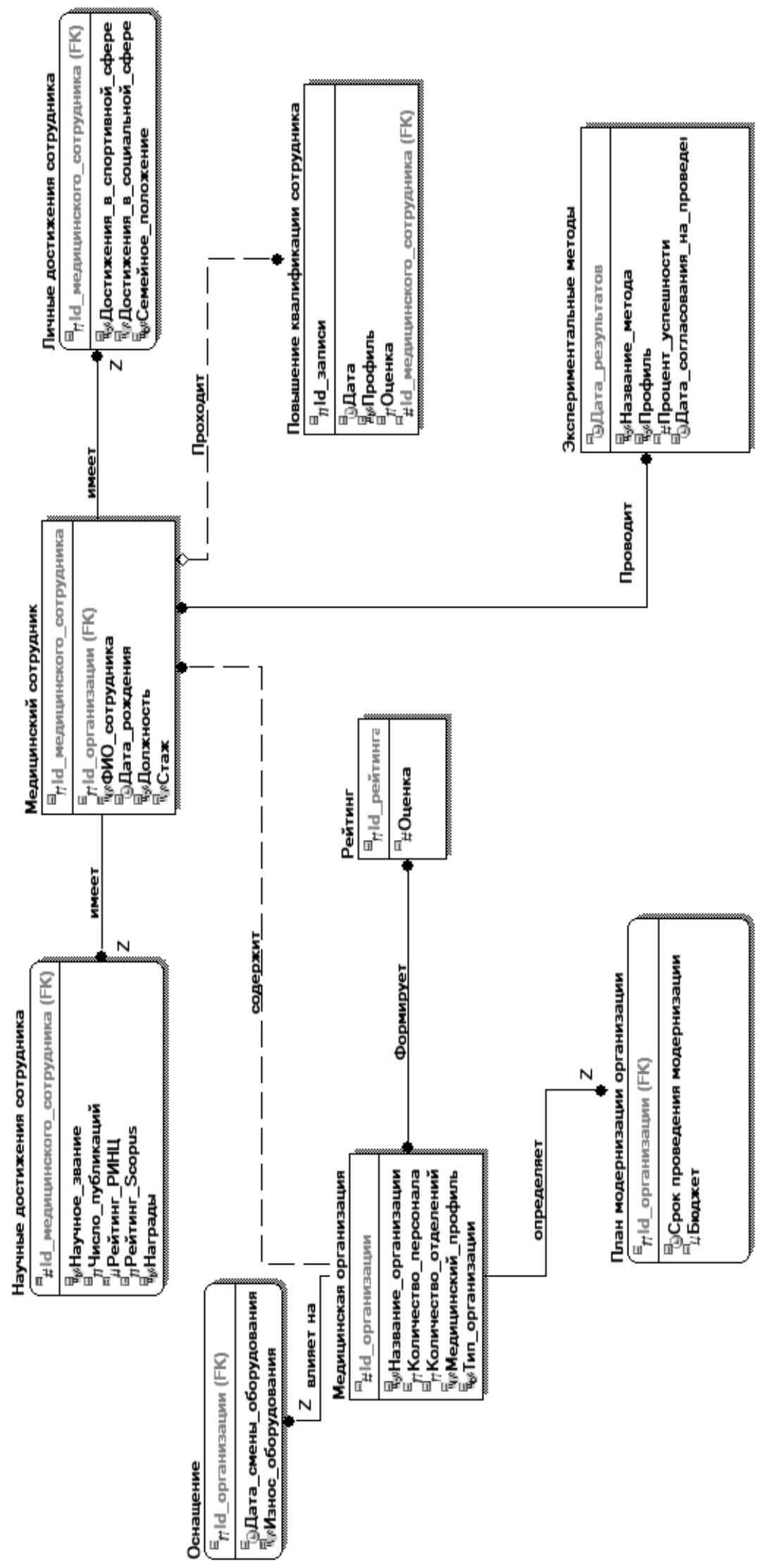

Рис. 9. Полная атрибутивная модель (логическая) БД ИС рейтингового оценивания деятельности организаций медико-социального профиля для управления региональной системой здравоохранения 


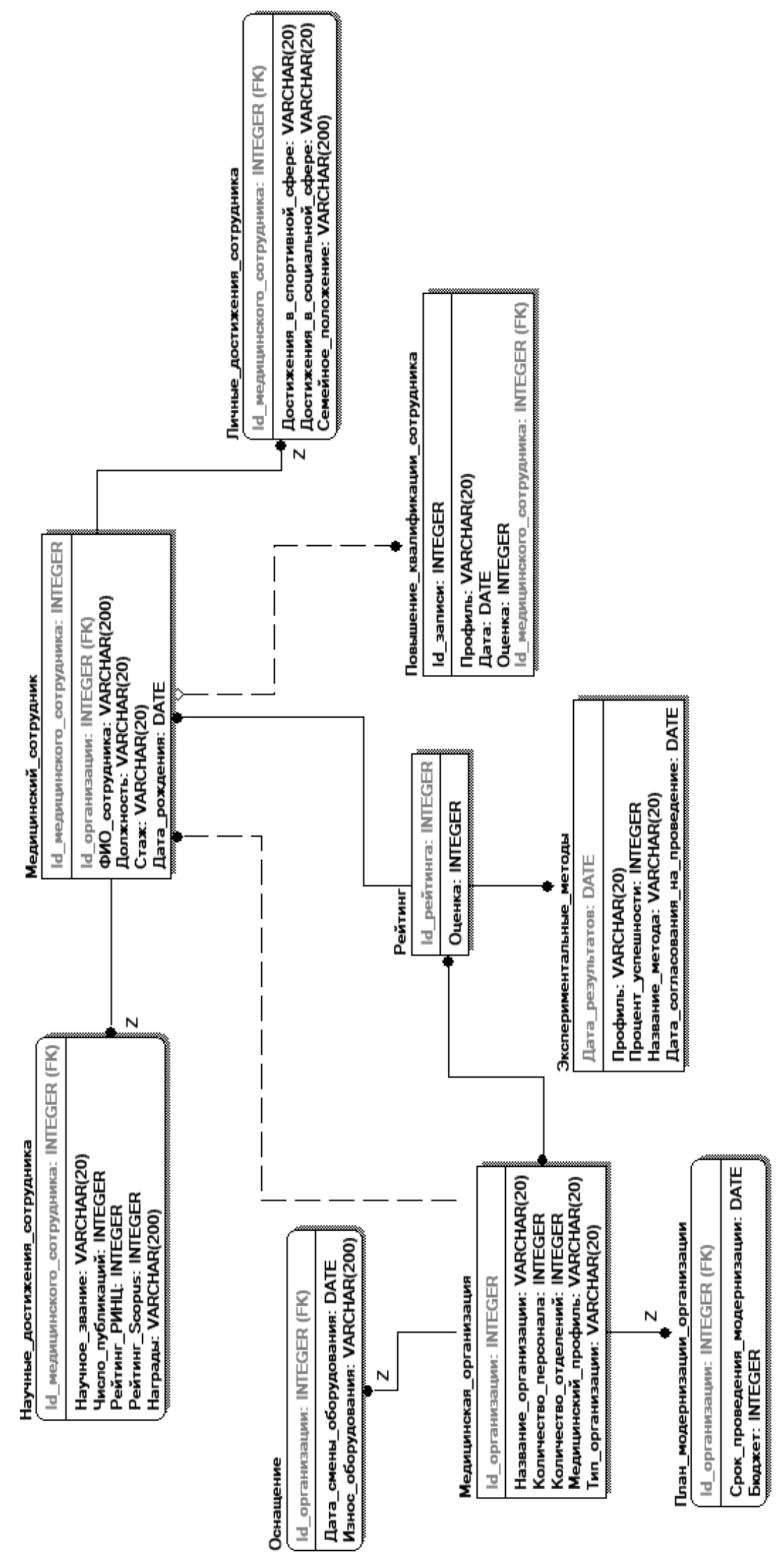

Рис. 10. Полная атрибутивная модель (физическая) БД ИС рейтингового оценивания деятельности организаций медико-социального профиля для управления региональной системой здравоохранения 
Для того, чтобы подготовить показатели для расчета, необходимо:

1. Вычислить рейтинг персонала;

2. Вычислить рейтинг научной эффективности;

3. Вычислить общий рейтинг организации;

4. Вычислить рейтинг технической оснащенности.

На основе вышеизложенного, составляется итоговая рейтинговая оценка [9-11].

\section{СозАание модели базы $\triangle$ бных \\ информационной системы \\ рейтингового оценивания \\ Аеяте^ьности организаций \\ меАико-социа^ьного профиль}

Для разработки модели базы данных (БД) информационной системы (ИС) рейтингового оценивания деятельности организаций медико-социального профиля для управления региональной системой здравоохранения применялось программное средство CA ERwin Data Modeler, интегрированное с CA ERwin Process Modeler и имеющее функционал для создания структуры данных проектируемой системы. Основой для создания структуры будущей ИС служит разработанная ранее модель бизнес-процессов. CA ERwin Data Modeler имеет возможность представить модель на логическом и физическом уровне. На логическом уровне создается полная атрибутивная модель, диаграмма сущность-связь и модель данных, основанная на ключах [12-14]. К физическому уровню относится трансформационная модель БД.

Все данные о сущностях, имеющихся в модели БД ИС рейтингового оценивания деятельности организаций медико-социального профиля и их определения представлены в таблице 2.

На рисунках 9 и 10 отражены полные атрибутивные (физическая и логическая модели FA-модель) БД ИС рейтингового оценивания деятельности организаций медико-социального профиля, представляющие отношения модели в третьих нормальных формах и включающие все сущности, атрибуты и связи между ними (таблица 1).

\section{$\mathrm{BuBO} \triangle$}

Созданные модели существующих бизнес-процессов и БД далее будут использованы при разработке ИС рейтингового оценивания деятельности организаций медико-социального профиля для управления региональной системой здравоохранения. Они также могут быть использованы для анализа процессов управления отдельными организациями здравоохранения, применимы для выполнения прогнозирования и планирования их деятельности [15].

\section{ЛИТЕРАТУРА}

1. Пономарева Л.А., Ромашкова 0. Н., Василюк И. П. Алгоритм оценки эффективности работы кафедр университета для управления его рейтинговыми показателями // Вестник Рязанского государственного радиотехнического университета. 2018. № 64. С. 102-108.

2. Ромашкова 0.Н., Ермакова Т. Н. Моделирование информационных процессов управления образовательным комплексом // Вестник Российского университета дружбы народов. Серия: Информатизация образования. 2014. № 2. С. 122-129.

3. Ермакова Т.Н., Ромашкова 0. Н. Объединенная информационная модель управления образовательным комплексом // В книге: Информационно-телекоммуникационные технологии и математическое моделирование высокотехнологичных систем. материалы Всероссийской конференции с международным участием. Российский университет дружбы народов. 2015. С. 128-130.

4. Горелов Г.В., Ромашкова 0. Н. Оценка качества обслуживания в сетях с пакетной передачей речи и данных // Вестник Российского университета дружбы народов. Серия: Прикладная и компьютерная математика. 2003. Т. 2. № 1. С. 23-31.

5. Литвак Б.Г., Стефановский Д. В. Моделирование и построение глобального управленческого цикла // В книге: Управление развитием крупномасштабных систем (MLSD'2011). Материалы пятой международной конференции. 2011. С. 124-126.

6. Стефановский Д. В. Проблемы извлечения данных из социальных сетей // В сборнике: Социальный компьютинг: основы, технологии развития, социально-гуманитарные эффекты (ISC-14). Материалы третьей Международной научно-практической конференции. 2014. С. 147-150.

7. Gaidamaka, Y.V., Romashkova, O. N., Ponomareva, L.A., Vasilyuk, I. P. Application of information technology for the analysis of the rating of university // CEUR Workshop Proceedings 8. Cep. "ITTMM 2018 - Proceedings of the Selected Papers of the 8th International Conference "Information and Telecommunication Technologies and Mathematical Modeling of High-Tech Systems'"' 2018. С. 46-53.

8. Ромашкова О.Н., Ермакова Т.Н. Мониторинг качества образования в средней общеобразовательной организации с использованием современных средств информатизации // Вестник Российского университета дружбы народов. Серия: Информатизация образования. 2014. № 4. С. $10-17$.

9. Ромашкова 0.Н., Пономарева Л. А., Василюк И. П. Применение информационных технологий для анализа показателей рейтинговой оценки вуза //В книге: Информационно-телекоммуникационные технологии и математическое моделирование высокотехнологичных систем. Материалы Всероссийской конференции с международным участием. 2018. С. 65-68.

10. Romashkova, 0.N., Ponomareva, L.A., Chiskidov, S.V. Instrumental implementation of the educational process model to improve the rating of the universities // CEUR Workshop Proceedings 8. Cep. "ITTMM 2019 — Proceedings of the Selected Papers of the 8th International Conference "Information and Telecommunication Technologies and Mathematical Modeling of High-Tech Systems'"' 2019. C. 92-101 
11. Romashkova, 0.N., Ponomareva, L.A., Vasiluk, I. P. The process of automating the rating of Russian universities // CEURWorkshop Proceedings 8. Cep. "ITTMM 2019 — Proceedings of the Selected Papers of the 8th International Conference"Information and Telecommunication Technologies and Mathematical Modeling of High-Tech Systems"'"'2019. C. 109-117.

12. Ромашкова 0.Н., Ломовцев Р.С., Пономарева Л. А. Компьютерная поддержка принятия управленческих решений для образовательной системы регионального уровня // Вестник Рязанского государственного радиотехнического университета. 2019. № 67. С. 50-58.

13. Ромашкова 0.Н., Самойлов В.Е. К определению качества пакетной передачи речи в сетях подвижной связи // Наукоёмкие технологии в космических исследованиях Земли. 2017. Т. 9. № 3. С. 39-44.

14. Заболотникова В.С., Ромашкова 0.Н. Информационная управленческая система для налоговой службы // Современная наука: актуальные проблемы теории и практики. Серия «Естественные и технические науки».-2017. -№ 6. -С. $27-32$.

15. Ромашкова 0.Н., Ермакова Т. Н. Методика выбора информационной модели для оценки показателей качества обучения // Вестник Российского университета дружбы народов. Серия: Информатизация образования. 2015. № 2. С. 14-20.

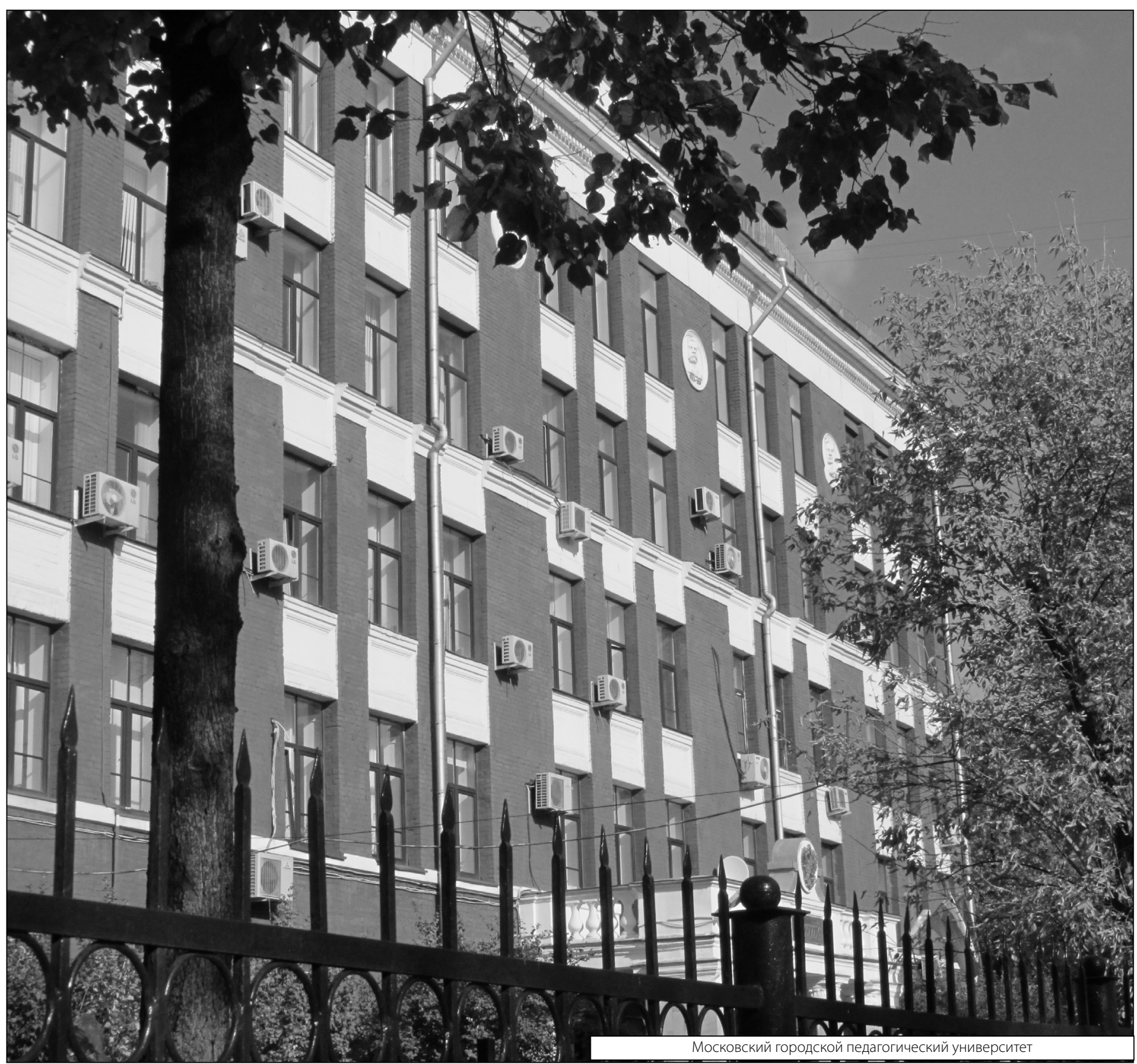

